\title{
Development of Phosphatidyl Glycerol Biosynthesis in the Lungs of Fetuses of Diabetic Rats
}

\author{
U.J.Eriksson ${ }^{1}$, O. Tydén ${ }^{2}$ and C. Berne ${ }^{3}$ \\ ${ }^{1}$ Department of Medical Cell Biology, ${ }^{2}$ Department of Obstetrics and Gynaecology, ${ }^{3}$ Department of Internal Medicine, University of Uppsala, \\ Uppsala, Sweden
}

\begin{abstract}
Summary. The lungs of fetuses of streptozotocin-diabetic rats were examined for their ability to incorporate $\mathrm{U}-{ }^{14} \mathrm{C}$-glucose into phosphatidyl choline, phosphatidyl glycerol, phosphatidyl inositol and lysophosphatidyl choline. In the lungs of control rats an increased biosynthesis of phosphatidyl glycerol in late pregnancy suggested a close association between the production of this phospholipid and the terminal maturation of the fetal lung. In the offspring of diabetic rats the incorporation of ${ }^{14} \mathrm{C}$-glucose into phosphatidyl choline, lysophosphatidyl choline and phosphatidyl glycerol was markedly decreased compared with the control rats on gestational day 20 , whereas no difference was seen at day 22. Insulin treatment of the pregnant rats restored the biosynthesis of phosphatidyl
\end{abstract}

choline and lysophosphatidyl choline towards normal on gestational day 20 , while the ratio of phosphatidyl glycerol to phosphatidyl inositol incorporation of ${ }^{14} \mathrm{C}$-glucose was decreased, suggesting that the biosynthesis of phosphatidyl glycerol is more sensitive than that of phosphatidyl choline and lysophosphatidyl choline to the metabolic disturbances inherent in maternal diabetes. The delayed fetal pulmonary maturation occurred without fetal hyperinsulinism which suggests that this latter feature may not be of crucial significance in the aetiology of the respiratory distress syndrome.

Key words: Phosphatidyl glycerol, diabetic pregnancy, fetal lung, rat.
Diabetes mellitus in the pregnant mother is associated with a delayed maturation of the fetal lung, leading to a high incidence of respiratory distress syndrome in the newborn [1-3]. In diabetic pregnancy, adequate production of the major surfactant phospholipid, disaturated phosphatidyl choline (lecithin) does not preclude the development of respiratory distress syndrome [4]. It has recently been claimed that the presence of the acidic phospholipid phosphatidyl glycerol (PG) in the amniotic fluid prevents respiratory distress syndrome in the newborn of the diabetic mother [4-6]. Delayed onset of the production of PG in the fetal lung may be one of the factors responsible for the decreased pulmonary surface activity predisposing to respiratory distress syndrome.

To elucidate this hypothesis further we have investigated the impact of maternal diabetes on PG production in relation to the biosynthesis of other surfactant phospholipids. For this purpose, we chose an experimental rat model which permits a study of well characterized degrees of glucose intolerance under strictly controlled conditions [7]. Using this model, we demonstrated previously that severe diabetes in the pregnant rat caused morphological immaturity and a decreased biosynthesis of phosphatidyl choline (PC) and lyso- phosphatidyl choline (LPC) in the fetal lung, as observed on gestational day 20 [8]. The aim of the present investigation was to examine the development of PG biosynthesis in late gestation in the fetuses of normal and diabetic rats; the incorporation of $\mathrm{U}-{ }^{14} \mathrm{C}$-glucose into PC, LPC, phosphatidyl inositol (PI) and PG in fetal lung was determined after separation of the phospholipids by two-dimensional thin-layer chromatography.

\section{Materials and Methods}

\section{Course and Termination of Pregnancy}

Manifest diabetes was induced in 3-month-old virgin Sprague-Dawley rats (Anticimex, Sollentuna, Sweden) by a single IV injection of streptozotocin (kindly donated by Dr. W.E.Dulin, Upjohn, Kalamazoo, Michigan, USA) in a dose of $45 \mathrm{mg} / \mathrm{kg}$ body weight. Animals with a non-fasting serum glucose concentration of $>22 \mathrm{mmol} / 1$ one week after the injection were classified as manifest diabetic.

Treatment with bovine insulin ultralente was commenced in half of the diabetic animals. The daily insulin dose (2-8 IU) was adjusted according to the serum glucose concentration, which was determined twice a week. Non-diabetic female rats of the same age and weight served as controls. All animals had access to commercially pelleted food (Ewos, Södertälje, Sweden) and water ad libitum. The animals were mated $2-5$ weeks after the streptozotocin injection. The day on 


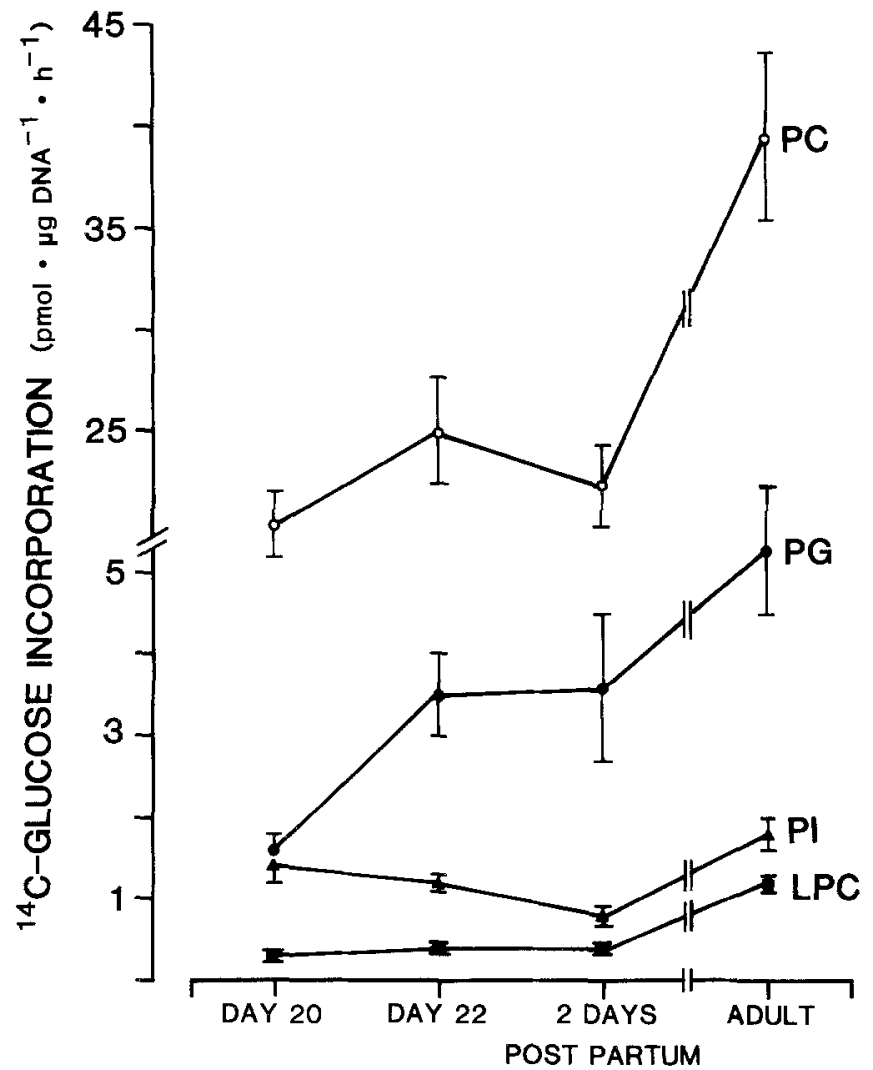

Fig. 1. Development of the biosynthesis of lung phospholipids in normal rat offspring in the perinatal period. Values from adult rats are included for comparison. Each point represents the mean \pm SEM of four to seven determinations, corresponding to number of litters or adult animals, and shows the incorporation of ${ }^{14} \mathrm{C}$-glucose into phosphatidyl choline $\mathrm{O}_{-} \mathrm{O}$ phosphatidyl glycerol $-\longrightarrow$, phosphatidyl inositol

and lysophosphatidyl choline

which a sperm-containing vaginal smear was found was denoted gestational day 0 . The normal rats give birth spontaneously in the late afternoon of gestational day 22, and the diabetic and insulin-treated diabetic rats 1-5 days later [7]. On gestational days 20 and 22, the pregnant rats were killed by a blow on the neck. The fetuses were quickly dissected from the uterus and decapitated. The right lungs of three to six fetuses from each litter were excised and placed in ice-cold Hanks' medium [9]. In addition, lungs from spontaneously born normal offspring with a postnatal age of 2 days and lungs from adult, non-pregnant female rats were included for comparative purposes.

\section{Incubation Protocol}

The pooled lungs were cut into pieces (approximately $1 \mathrm{~mm}^{3}$ ) in icecold Hank's medium. Duplicate samples of 10-15 pieces from each batch were transferred into $100 \mu \mathrm{l}$ of a Gey-Gey buffer [10], $\mathrm{pH} 7.4$, equilibrated with $\mathrm{O}_{2}: \mathrm{CO}_{2}(95 \%: 5 \%)$ and containing D-U- ${ }^{14} \mathrm{C}$-glucose $(5.5 \mathrm{mmol} / 1$, spec. act. $18 \mathrm{mCi} / \mathrm{mmol})$. After incubation in a shaking water bath for $90 \mathrm{~min}$ under an atmosphere of $\mathrm{O}_{2}: \mathrm{CO}_{2}(95 \%: 5 \%)$, the reaction was terminated by the addition of D-glucose $(200 \mu \mathrm{l}$, $28 \mathrm{mmol} / 1)$. The lung pieces were then washed twice in a salt solution [11] and disrupted ultrasonically for 20-30 s (Ultrasonic Disintegrator, MSE, London, UK) in $150 \mu \mathrm{l}$ of the washing solution.

\section{Extraction of the Phospholipids}

After removal of duplicate samples $(10 \mu \mathrm{l})$ for DNA estimation $[12,13]$, the lung homogenate was extracted for $1 \mathrm{~h} \mathrm{in} 2 \mathrm{ml}$ of $\mathrm{CHCl}_{3}$ :
$\mathrm{MeOH}(2: 1)$ containing $30 \mu 1$ of carrier egg yolk lipids (Vitrum, Stockholm, Sweden). The lipid extract was washed $\times 4$ to remove watersoluble radioactivity as described by Folch et al. [11] and the lipidcontaining lowe phase $(1 \mathrm{ml})$ was evaporated to dryness under $\mathrm{N}_{2}$ and redissolved in $50 \mu \mathrm{l}$ of $\mathrm{CHCl}_{3}: \mathrm{MeOH}(2: 1)$ containing $20 \mu \mathrm{l}$ of a mixture of chromatographically pure phospholipids $(2.5 \mathrm{mg} / \mathrm{ml}$ of each phospholipid). These lipids were: dipalmitoyl-PC, PI, PG, phosphatidyl ethanolamine (Sigma Chemicals, St. Louis, MO, USA), phosphatidyl serine, LPC and sphingomyelin (Koch-Light Laboratories, Colnbrook, Bucks, UK).

\section{Separation of Phospholipids}

The lipid extract $(30 \mu l)$ was spotted onto pre-coated plates of silica gel G (Merck, Darmstadt, FRG) and run $10-15 \mathrm{~cm}$ in a twodimensional system [14] using $\mathrm{CHCl}_{3}: \mathrm{MeOH}: \mathrm{H}_{2} \mathrm{O}: \mathrm{CH}_{3} \mathrm{COOH}$ $(65: 25: 4: 8)$ in the first direction and tetrahydrofuran: formaldehydedimethylacetal: $\mathrm{MeOH}: 2 \mathrm{~N} \quad \mathrm{NH}_{4} \mathrm{OH}(40: 28.5: 7.8: 4.2)$ in the second direction. After drying, the plates were sprayed with $2^{\prime}, 7^{\prime}$ dichlorofluorescein and the phospholipids visualized in ultraviolet light. The spots corresponding to PG, PC, PI and LPC were scraped off into vials containing MeOH $(150 \mu \mathrm{l})$ [15] and Econofluor $(2.5 \mathrm{ml}$, New England Nuclear, Boston, MA, USA) was added. Radioactivity was measured in a Packard Scintillation Counter, model 3255 (Packard Instruments, Downers Grove, IL, USA) with correction for quenching by the channels ratio method.

\section{Statistics}

Statistical calculations in the offspring and adult animals were based on the numbers of litters or individual adult animals, respectively. Probabilities $(p)$ of chance differences between the different groups were estimated by Student's two-tailed t-test [16].

\section{Results}

\section{Lung Phospholipid Biosynthesis in Normal Animals}

The normal development of the biosynthesis of $\mathrm{PC}, \mathrm{PG}$, LPC and PI from gestational day 20 up to adulthood can be seen in Figure 1. The major increase in PC production occurred after the immediate neonatal period. The biosynthesis of LPC showed an analogous development, the major increase towards adult values being noted after the second postnatal day. The development of PG, however, exhibited a different pattern, with a rapid increase between days 20 and 22 , a plateau during the neonatal period and a less pronounced increase up to adult values. Oniy the PI biosynthesis tended to decrease throughout the perinatal period, from 1.4t $0.2 \mathrm{pmol} \cdot \mu \mathrm{g} \mathrm{DNA} \mathrm{gN}^{-1} \cdot \mathrm{h}^{-1}$ on day 20 to $0.8 \pm 0.1 \mathrm{pmol}$. $\mu \mathrm{gNA}^{-1} \cdot \mathrm{h}^{-1}$ on day 2 after birth $(0.05<p<0.10)$.

\section{Lung Phospholipid Biosynthesis in the Fetuses of Manifest Diabetic Mothers}

The rates of biosynthesis of the four phospholipids on gestational days 20 and 22 are shown in Table 1 . On day 20 , the incorporation of ${ }^{14} \mathrm{C}$-glucose into all of the phospholipids except PI was decreased. On day 22 , however, the fetal lung phospholipid biosynthesis had accelerated markedly and was not significantly differ- 
Table 1. Phospholipid biosynthesis in the rat fetal lung on gestational days 20 and 22

\begin{tabular}{|c|c|c|c|c|c|c|}
\hline & \multicolumn{6}{|c|}{ D-U- ${ }^{14} \mathrm{C}$-glucose incorporation } \\
\hline & \multicolumn{3}{|c|}{ Gestational day 20} & \multicolumn{3}{|c|}{ Gestational day 22} \\
\hline & $\begin{array}{l}\text { Control } \\
\text { rats }\end{array}$ & $\begin{array}{l}\text { Manifest } \\
\text { diabetic rats }\end{array}$ & $\begin{array}{l}\text { Insulin } \\
\text { treated rats }\end{array}$ & $\begin{array}{l}\text { Control } \\
\text { rats }\end{array}$ & $\begin{array}{l}\text { Manifest } \\
\text { diabetic rats }\end{array}$ & $\begin{array}{l}\text { Insulin } \\
\text { treated rats }\end{array}$ \\
\hline Number of litters & 8 & 10 & 11 & 9 & 10 & 7 \\
\hline Phosphatidyl choline & $20.2 \pm 1.6$ & $12.9 \pm 0.8^{\mathrm{c}}$ & $18.7 \pm 1.2^{\mathrm{f}}$ & $25.0 \pm 2.6$ & $22.8 \pm 2.5$ & $29.1 \pm 2.7$ \\
\hline Lysophosphatidyl choline & $0.34 \pm 0.05$ & $0.23 \pm 0.02^{b}$ & $0.35 \pm 0.03^{\mathrm{e}}$ & $0.45 \pm 0.03$ & $0.39 \pm 0.02$ & $0.64 \pm 0.07^{\mathrm{b}, \mathrm{d}}$ \\
\hline Phosphatidyl glycerol & $1.6 \pm 0.2$ & $0.5 \pm 0.1^{\mathrm{c}}$ & $0.9 \pm 0.1^{\mathrm{d}}$ & $3.5 \pm 0.5$ & $3.1 \pm 0.5$ & $3.9 \pm 0.5$ \\
\hline Phosphatidyl inositol & $1.4 \pm 0.2$ & $1.1 \pm 0.1$ & $1.6 \pm 0.1$ & $1.2 \pm 0.1$ & $1.2 \pm 0.1$ & $1.5 \pm 0.2$ \\
\hline $\mathrm{PG} / \mathrm{PI}^{\mathrm{a}}$ & $1.5 \pm 0.5$ & $0.5 \pm 0.2^{b}$ & $0.6 \pm 0.1^{\mathrm{b}}$ & $3.1 \pm 0.3$ & $2.6 \pm 0.3$ & $2.6 \pm 0.2$ \\
\hline
\end{tabular}

The results are expressed as pmol $\cdot \mu \mathrm{g} \mathrm{DNA}^{-1} \cdot \mathrm{h}^{-1}$ (mean $\left.\pm \mathrm{SEM}\right)$

${ }^{a}$ PG/PI denotes the ratio between the rates of incorporation into phosphatidyl glycerol and phosphatidyl inositol. Significances:

${ }^{\mathrm{b}} p<0.05 ;{ }^{\mathrm{c}} p<0.001$ versus control fetuses of the same age; ${ }^{\mathrm{d}} p<0.05 ;{ }^{\mathrm{e}} p<0.01 ;{ }^{\mathrm{f}} p<0.001$ versus fetuses of the same age from manifest diabetic rats

ent from that in the controls, although a tendency towards lowered average levels was observed. Consequently, the PG/PI ratio of ${ }^{14} \mathrm{C}$-glucose incorporation in the fetuses of diabetic mothers increased significantly between gestational days 20 and $22(p<0.001)$.

\section{Lung Phospholipid Biosynthesis in the Fetuses of Insulin-Treated Diabetic Mothers}

Insulin treatment of the mother markedly influenced the development of fetal lung phospholipid biosynthesis. On gestational day 20 the biosynthetic rates of all phospholipids (Table 1) in the fetuses of insulin-treated diabetic mothers were in the normal range. On that day, however, the $\mathrm{PG} / \mathrm{PI}$ ratio of incorporation was significantly below that in the controls. Two days later, the lungs of fetuses from insulin-treated diabetic mothers showed a PG/PI ratio in the normal range, the production of PC was normal and that of LPC was slightly increased compared with the normal and manifest diabetic groups.

\section{Discussion}

In rat fetuses a considerable acceleration of lung maturation occurs between gestational day 20 and birth [17]. Therefore, the present investigation on the impact of maternal diabetes upon lung maturation appertained to this particular period of gestation.

In confirmation of the results obtained with tritiated choline [8], we observed a similar trend towards increased phosphatidyl choline biosynthesis between day 20 and day 22 and a further increase up to adult values using ${ }^{14} \mathrm{C}$-glucose. $\mathrm{PC}$ was responsible for the greatest fractional incorporation of radioactivity from ${ }^{14} \mathrm{C}$ glucose, reaching $85 \%$ of the total phospholipids. An increase in the phosphatidyl glycerol biosynthesis of $>100 \%$ between days 20 and 22 is consistent with the idea of a strong link between accelerated PG produc- tion and the terminal maturation of the fetal lung [18-20].

In the offspring of manifest diabetic rats the $70 \%$ reduction of PG biosynthesis accompanied by a minor inhibition of phosphatidyl inositol biosynthesis on day 20 indicates that one of the major consequences of maternal diabetes is disturbed regulation of the enzymatic steps diverting cytidine diphosphoglyceride from PI to PG production in late pregnancy. The other major effect of maternal diabetes on the biochemical maturation of fetal lungs was marked impairment of the biosynthesis of PC and lysophosphatidyl choline in the fetuses of the manifest diabetic rats, irrespective of whether ${ }^{3} \mathrm{H}$ choline or ${ }^{14} \mathrm{C}$-glucose was used as the precursor. This observation, which has been found to be connected with signs of morphological immaturity of Type II pneumocytes [8] led to the speculation that the production of disaturated PC through the 'LPC pathway' [21] could be inhibited in the fetuses of manifest diabetic rats. The demonstration in lung lavage, of reduced disaturated PC in fetuses of alloxan-diabetic rabbits [22] and in the newborn of streptozotocin-diabetic rat mothers [23] supports this conclusion.

Correction of the maternal metabolic disturbance by insulin treatment was accompanied by a return to normal of surfactant biosynthesis in the fetus. On day 20 of gestation the sole exception was only partial correction of PG biosynthesis, as shown by the decreased ratio of incorporation of ${ }^{14} \mathrm{C}$-glucose into $\mathrm{PG}$ and PI. Interestingly, this finding has a parallel in the development of human diabetic pregnancy, in which the maturation of $\mathrm{PC}$ biosynthesis precedes that of $\mathrm{PG}$ $[4,5]$, indicating that the delicate mechanism regulating the terminal rise in $P G$ production is very sensitive to the metabolic disturbance caused by maternal diabetes, even when insulin treatment has resulted in near-normalization of the blood glucose.

In an attempt to explain the delayed lung maturation in diabetic pregnancy, the frequently observed fetal hyperinsulinism, which is responsible for several of the 
features of the diabetic fetopathy syndrome has been invoked to play a role. In studies performed in vitro, insulin inhibits the corticosteroid - induced increase in PC biosynthesis in fetal lungs $[24,25]$. Recently Gross et al. [26] reported an inhibition of the production of disaturated $\mathrm{PC}$ in fetal rabbit lungs in organ cultures after $24 \mathrm{~h}$ of exposure to insulin. On the other hand, insulin stimulates biosynthesis of glycogen, structural lipids and PG. Therefore, factors other than insulin must participate in the process leading to the inhibition of both $\mathrm{PC}$ and $\mathrm{PG}$ production in diabetic pregnancy. Indeed, further characterization of the fetal endocrine pancreas in the manifest diabetic group has shown retarded development of the $B$ cells [7,27-29]. Direct measurement of serum insulin in these fetuses [8] and in the offspring of alloxandiabetic rabbits [22] has failed also to demonstrate hyperinsulinism. The fact that the retarded development of the rat fetal lung occurs without fetal hyperinsulinism $[8,30,31]$ suggests that this latter feature is not of crucial significance to the aetiology of delayed pulmonary maturation in man [32].

Other possible explanations for the delayed lung maturation in diabetic pregnancy may involve a shortage of substrate for phospholipid biosynthesis, e. g. fatty acids [33]. Alternatively deficient corticosteroid action either in the production of hormone [34] or in the number of receptors [35] may lead to delayed induction of surfactant biosynthesis. Both lack of substrate and deficient corticosteroid action would lead to decreased production of both PG and disaturated PC, which could explain the mechanism of delayed lung maturation in diabetic pregnancy.

The present results underline the close association between enhanced biosynthesis of PG and late fetal lung development and lend support to the suggested measurement of PG in amniotic fluid as an index of pulmonary maturation. The study stresses the role of maternal diabetes in delayed biosynthesis of lung surfactant in the fetus, with the consequently increased risk of pulmonary immaturity in the case of pre-term delivery.

Acknowledgements. The authors wish to thank E. Wennberg and A. Nordin for expert technical assistance. This investigation was supported by The "Expressen" Prenatal Research Foundation, Syskonen Svensson's Fund for Medical Research, The Swedish Diabetes Association, The Swedish Society for Medical Research, The Medical Faculty of the University of Uppsala, and The Swedish Medical Research Council (B81-12X-00525-17A, 12X-109).

\section{References}

1. Gellis SS, Hsia DYY (1959) The infant of the diabetic mother. Am J Dis Child 97: 1-41

2. Usher RH, Allen AC, McLean FH (1971) Risk of respiratory distress syndrome related to gestational age, route of delivery and maternal diabetes. Am J Obstet Gynecol 111; 826-832

3. Robert MF, Neff RK, Hubbell JP, Taeusch HW, Avery ME (1976)
Association between maternal diabetes and the respiratory-distress syndrome in the newborn. N Engi J Med 294: 357-360

4. Cunningham MD, Desai NS, Thompson SA, Green JM (1978) Amniotic fluid phosphatidylglycerol in diabetic pregnancies. Am J Obstet Gynecol 131: 719-724

5. Kulovich MV, Gluck L (1979) The Iung profile. II. Complicated pregnancy. Am J Obstet Gynecol 135: 64-70

6. Hallman M, Teramo K (1979) Amniotic fluid phospholipid profile as a predictor of fetal maturity in diabetic pregnancies. Obstet Gynecol 54: 703-707

7. Eriksson U, Andersson A, Efendić S, Elde R, Hellerström, C (1980) Diabetes in pregnancy: effects on the foetal and newborn rat with particular regard to body weight, serum insulin concentration and pancreatic contents of insulin, glucagon and somatostatin. Acta Endocrinol 94: 354-364

8. Tydén O, Berne C, Eriksson U (1980) Lung maturation in fetuses of diabetic rats. Pediatr Res 14: 1192-1195

9. Hanks JH, Wallace RE (1949) Regulation of oxygen and temperature in the preservation of tissues by refrigeration. Proc Soc Exp Biol Med 71: 196-200

10. Gey GO, Gey MK (1936) The maintenance of normal cells and tumor cells in continuous culture. Am J Cancer 27: 45-49

11. Folch J, Lees M, Sloane-Stanley GH (1957) A simple method for the isolation and purification of total lipids from animal tissue. $\mathbf{J}$ Biol Chem 226: 497-509

12. Hinegardner RT (1971) An improved fluorometric assay for DNA. Anal Biochem 39: 197-201

13. Kissane JM, Robins E (1958) The fluorometric measurement of deoxyribonucleic acid in animal tissues with special reference to the central nervous system. J Biol Chem 233: 184-188

14. Kulovich MV, Hallman MB, Gluck L (1979) The lung profile. I. Normal pregnancy. Am J Obstet Gynecol 135: 57-63

15. Boberg J (1966) Separation of labelled plasma and tissue lipids by thin-layer chromatography. Clin Chim Acta 14: 325-334

16. Ostle B (1963) Statistics in research, 2nd ed. Ames, The Iowa State University Press

17. Maniscalco WM, Wilson CM, Gross I, Gobran L, Rooney SA, Warshaw JB (1978) Development of glycogen and phospholipid metabolism in fetal and newborn rat lung. Biochim Biophys Acta 530: $333-346$

18. Hallman M, Kulovich MV, Kirkpatrick E, Sugarman RG, Gluck L (1976) Phosphatidylinositol and phosphatidylglycerol in amniotic fluid: indices of lung maturity. Am J Obstet Gynecol 125: 613-617

19. Hallman M, Teramo K, Kankaanpää K, Kulovich MV, Gluck L (1980) Prevention of respiratory distress syndrome: current view of fetal lung maturity studies. Ann Clin Res 12: 36-44

20. Hallman M, Epstein BL (1980) Role of myo-inositol in the synthesis of phosphatidylglycerol and phosphatidylinositol in the lung. Biochem Biophys Res Commun 92: 1151-1159

21. Hallman M, Raivio KI (1975) Formation of disaturated lecithin through the lysolecithin pathway in the lung of the developing rabbit. Biol Neonate 27:329-338

22. Bose CL, Manne DN, Dercole I, Lawson EG (1980) Functional and biochemical alterations in lungs of fetuses of diabetic rabbits. Pediatr Res 12: 639 (Abstract)

23. Rhoades RA, Filler DA, Vannata B (1979) Influence of maternal diabetes on lipid metabolism in neonatal rat lung. Biochim Biophys Acta 572: $132-138$

24. Smith BT, Giroud CJP, Robert M, Avery ME (1975) Insulin antagonism of cortisol action on lecithin synthesis by cultured fetal lung cells. J. Pediatr 87: 953-955

25. Neufeld ND, Sevanian A, Barrett CT, Kaplan SA (1979) Inhibition of surfactant production by insulin in fetal rabbit lung slices. Pediatr Res 13: 752-754

26. Gross I, Smith GJW, Wilson CM, Maniscalco WM, Ingleson LD, Brehier A, Rooney SA (1980) The influence of hormones on the biochemical development of fetal rat lung in organ culture. II. Insulin. Pediatr Res 14: 834-838

27. Eriksson U, Hellerström C, Andersson A (1981) Diabetes in preg- 
nancy: effects on the maturation of (pro)insulin biosynthesis in foetal and neonatal rat islets. Diabéte Metab 7: 243-249

28. Eriksson U, Swenne I (1982) Diabetes in pregnancy: growth of the fetal pancreatic B cells in the rat. Biol Neonate $42: 239-248$

29. Swenne I, Eriksson U (1982) Diabetes in pregnancy: Islet cell proliferation in the fetal rat pancreas. Diabetologia $23: 525-528$

30. Eriksson U (1981) Diabetes in pregnancy: a rat model for the study of fetal complications. Upsala J Med Sci 86: 207-212

31. Kervran A, Guillaume M, Jost A (1978) The endocrine pancreas of the fetus from diabetic pregnant rat. Diabetologia 15: 387-393

32. Sosenko IR, Kitzmiller JL, Loo SW, Blix P, Rubenstein AH, Gabbay KH (1979) The infant of the diabetic mother. Correlation of increased cord C-peptide levels with macrosomia and hypoglycemia. N Engl J Med 301: 859-862

33. Nelson GH, McPherson J, Perling L, Ciechan R (1980) The effect of maternal dietary fat on fetal pulmonary maturation in rats. Am J Obstet Gynecol 138: 466-467

34. Guleff PS, Beck RR (1981) Maternal and fetal adrenocortical function in the diabetic rabbit. Am J Physiol 240: E217-E225

35. Boutwell WC, Goldman AS (1979) Depressed biochemical lung maturation and steroid uptake in an animal model of infant of diabetic mother. Pediatr Res 13:355 (Abstract)

Received: 5 March 1982

and in revised form: 10 November 1982

Dr. U.J. Eriksson

Department of Medical Cell Biology

Biomedicum, P.O. Box 571

S-751 23 Uppsala, Sweden 